\title{
Journalists criticize research on COVID-19 by confusing it with tobacco harm reduction and by making false allegations about conflicts
}

\author{
Konstantinos Farsalinos ${ }^{1}$
}

1 University of West Attica

Funding: The author received no specific funding for this work.

Potential competing interests: I am the author of several studies about COVID-19 and the cholinergic system, all of which were not funded by anyone. I am currently involved in a patent application concerning the use of pharmaceutical cholinergic agonists, monoclonal antibodies and diagnostic tests for COVID-19.

\begin{abstract}
A featured article in the BMJ, authored by journalists from the Investigative Desk, criticize research about COVID-19 and the cholinergic system by confusing it with tobacco harm reduction and nonpharmaceutical nicotine products. Their criticism is not based on an assessment of the studies content but on allegations about conflicts. I present the case that such allegations are false, and I provide documents showing that the journalists have conflicts of interest relevant to their article content that were not disclosed. Additionally, I present evidence on the link between COVID-19 and the cholinergic system, which form the basis for clinical trials to examine the effect of pharmaceutical cholinergic agonists in COVID-19 prevention and treatment.
\end{abstract}

\section{Introduction}

Recently, the BMJ featured an article by journalists-members of the Investigative Desk claiming that research on COVID-19 and the cholinergic system is linked to tobacco industry and tobacco harm reduction interests to promote nicotine [1]. The journalists claim that my research on COVID-19 has been motivated by commercial tobacco and nicotine interests, and that I have not properly disclosed my conflicts of interest in my studies. The BMJ article is the last of a series of articles in news media with similar content over the past 6 months [2,3]. In their latest article, the journalists not only repeat their allegations but they also mis-present scientific evidence about risk factors for COVID-19 and about the purpose and aims of my research work on COVID-19. In this article, I explain why their allegations about undisclosed conflicts are wrong, I present a short overview of my research on COVID-19, which is relevant to the cholinergic system and has nothing to do with tobacco harm reduction, and I provide evidence, through documents obtains from a Freedom of Information Act request, proving that the journalists have undisclosed conflicts of interest which are relevant to the content of their article. While I repeatedly tried to submit a response 
online to the BMJ featured article (as a rapid response), none of my responses was ever published. Similarly, none of my letters to the media that published articles from The Investigative Desk journalists were ever released publicly by the media. The aim of this article is not to engage into a conflict between two parties but to restore transparency, through the presentation of undisclosed facts, and to explain the purpose and goals of research that explores the possibility that medications (cholinergic agonists) may have a therapeutic role in COVID-19.

\section{Funding and conflicts of interest}

The authors of the BMJ featured article present me as an employee of the Laboratory of Immunology and Molecular Biology of the University of Patras, and that I should have declared all conflicts relevant to the activities and collaborations of the director of the Laboratory. However, they were informed through my response (dated November 21,2020 ) that I am a non-paid external associate at the Laboratory and that I have not received any salary, payment, remuneration, material or other forms of compensation from it [4]. The latter excludes me from any conflict of interest relevant to the Laboratory and its Director. Although the journalists could have independently verified this information, by asking the University or the Laboratory, and should have provided such documentation as proof for their claims, it is unclear if they made such an attempt. Of course, I have never participated in any Laboratory project funded by commercial entities, and I am in no position to know or be involved in any agreements that the Laboratory makes with commercial or non-commercial entities. Similarly, I have no connection with, and I have not participated in any activities of the Patras Science Park and the NOSMOKE startup, which appear in the BMJ article as recipients of funding from the Foundation for a Smoke Free World.

The journalists claim that I do not present my past conflicts of interest in the studies I publish. This is a false allegation. Not only do I report all relevant conflicts and funding in full transparency in all my publications, but I also report them for far longer than the 36-months period dictated by the International Committee of Medical Journal Editors [5]. For example, funding (not "fee", as falsely mentioned by the journalists) provided by the American E-Liquid Manufacturing Standards Association (which is a non-profit association) for a research project in 2013, resulting in two publications in 2014 and 2015 [6,7], was reported not only in the relevant publications but also in several other publications and as late as 2020 ( 7 years after the funding was received) [8]. Additionally, the meeting with the US regulators presenting results from this research project was also reported in the relevant publications $[6,7]$ but, again, no fee was received for this meeting. Finally, all my research on COVID-19 was never funded by any entity and is irrelevant to my past research on tobacco harm reduction (as I explain below).

Ironically, the authors discuss about conflicts of interest but they fail to present their own conflicts of interest, specifically their funding from the University of Bath and from the Bloomberg Foundation through the University of Bath. Funding from the University of Bath is disclosed in the website of the Investigative Desk [9], but not in the BMJ article [1]. Additionally, documents obtained through a Freedom of Information Act request from the University of Bath on February 5, 2021, show that not only was the Investigative Desk 
funded by the University $[10,11]$, but it also received funding from Bloomberg Foundation through the University of Bath [12]. While it is unclear if the funding was provided for the specific BMJ article, one of the documents mentions work on services with anticipated completion end of December 2020. This coincides with a similar article authored by the Investigative Desk in a French newspaper [2]. In any case, this represents an undisclosed conflict of interest that is relevant to the article content, since it has been reported that the Bloomberg Foundation has an anti-tobacco harm reduction agenda [13-15] and the journalists tried to discredit research on COVID-19 by linking this research to my research on tobacco harm reduction. Notably, they never questioned the accuracy of the content, analysis, presentation or interpretation of any of my studies. Still, it needs to be emphasized that my research activities on COVID19 are irrelevant to tobacco harm reduction.

\section{Research on COVID-19 and the cholinergic system}

All the discussion about conflicts is irrelevant to my research on COVID-19. The latter involves a potential interaction between SARS-CoV-2 and the cholinergic system. None of my work on COVID-19 was funded by any commercial or non-commercial entity. Perhaps due to their lack of expertise, the authors of the BMJ article fail to understand the fundamental difference between this research subject and my previous and on-going research on tobacco harm reduction and non-pharmaceutical nicotine products. It is characteristic that none of my studies on COVID-19 contain any reference, direct or indirect, to tobacco harm reduction. My work on COVID-19 explores the possibility that pharmaceutical cholinergic agonists have a therapeutic role in preventing and/or treating the disease. This is based not only on indirect observational data about the association between smoking and COVID-19, but also on in silico experiments [16]. Observational data on smoking and COVID-19 have been reported by several research groups. OpenSafely, a dataset of primary care records of 17.3 million adults in the UK, reported that current smoking was associated with an 11\% lower chance of COVID-19 related death [17]. The authors of the BM] article selectively presented the results of the analysis adjusting for age and sex only, but failed to present the fully-adjusted model. This may be justified due to their lack of expertise, but their statement is not correct. OpenSafely reported that current smoking was associated with lower risk for of COVID-19 related death. Recently, a study published in the journal "Heart" (member of the BMJ Group) reported that heavy smokers were $88 \%$ less likely to be admitted to the ICU due to COVID-19, and 52\% less likely to be diagnosed with COVID-19 [18]. Similarly, another study from Germany found that smokers were $72 \%$ less likely to be diagnosed with COVID-19 [19]. Several other studies from Italy, France, Israel, UK, USA, Chile and South Korea reported similar results [20-26]. All studies from different research groups verify or expand on my findings that smokers are under-represented among hospitalized COVID-19 patients. It should be emphasized that neither myself nor any other researcher reporting similar findings have ever suggested that smoking, one of the strongest preventable risk factors for a plethora of diseases, could ever be used for the prevention or treatment of COVID-19. Instead, this is indirect observational evidence which, combined with in silico experiments and established knowledge about the cholinergic anti- 
inflammatory pathway, has been used to generate a hypothesis about a potential interaction between SARS-CoV-2 and the cholinergic system. My hypothesis suggests a therapeutic effect for pharmaceutical cholinergic agonists $[16,27]$. In one of my studies, I mentioned choline, nicotine, galantamine and varenicline, all of which are medications that could be studied for their role in COVID-19 due to their action as alpha 7 acetylcholine receptor agonists [16]. Such a hypothesis is biologically plausible, considering the known properties of the cholinergic anti-inflammatory pathway in modulating the immune response and the fact that severe COVID-19 is associated with a hyper-inflammatory response $[27,28]$. Any hypothesis that may be generated from indirect observational evidence and in vitro or in silico experiments suffers from limitations, which have been comprehensively presented in all my studies. Still, the data form the basis for conducting clinical trials with pharmaceutical cholinergic agonists, which is the only way of verifying or rejecting a scientific hypothesis. The authors of the featured article have obviously misunderstood my research on COVID-19, which is not surprising considering their lack of expertise; therefore, I emphasize once again that the evidence on the association between smoking and COVID-19, which has been reported by several research groups, has been used in order to generate and test a hypothesis about the potential therapeutic effects of pharmaceutical cholinergic agonists on COVID-19. Such clinical trials have been proposed by others and are already underway [29-31].

\section{Conclusion}

In conclusion, journalists with undisclosed conflicts of interest made an effort to discredit research for COVID-19 by confusing such research with tobacco harm reduction, and by making false allegations about conflicts of interest relevant to COVID-19 research which in fact was not funded by any entity. They also mis-presented published evidence about the association between risk factors and COVID-19. It is particularly worrying that the BMJ featured article remains unanswered, because such efforts may discourage other scientists from presenting research findings accurately and unbiased due to feat that they may be the subject of similar false allegations. It is important that research on COVID-19 prevention and treatment continues, and current evidence forms the basis for conducting clinical trials to evaluate the potential effect of pharmaceutical cholinergic agonists on COVID-19 susceptibility and severity.

\section{Statement on Competing Interests.}

I am the author of several studies about COVID-19 and the cholinergic system, all of which were not funded by anyone. I am currently involved in a patent application concerning the use of pharmaceutical cholinergic agonists, monoclonal antibodies and diagnostic tests for COVID-19.

\section{References}

1. Horel S, Keyzer T. Covid 19: How harm reduction advocates and the tobacco industry capitalised on the pandemic to promote nicotine. BMJ. 2021 Jun 2;373:n1303. doi: 10.1136/bmj.n1303.

2. Le Monde. Petites ficelles et grandes manœuvres de l'industrie du tabac pour réhabiliter la nicotine. 
Available at: https://www.lemonde.fr/planete/article/2020/12/19/petites-ficelles-et-grandes-man-uvresde-l-industrie-du-tabac-pour-rehabiliter-la-nicotine_6063922_3244.html.

3. International Committee of Medical Journal Editors. Disclosure of Interest (Updated February 2021). Available at: http://www.icmje.org/downloads/coi_disclosure.docx.

4. Farsalinos K. Personal communication by email with a member of The Investigative Desk. November 21, 2020. Available at: https://tinyurl.com/bx5x3xjk.

5. International Committee of Medical Journal Editors. Disclosure of Interest (Updated February 2021). Available at: http://www.icmje.org/downloads/coi_disclosure.docx.

6. Farsalinos KE, Spyrou A, Tsimopoulou K, Stefopoulos C, Romagna G, Voudris V. Nicotine absorption from electronic cigarette use: comparison between first and new-generation devices. Sci Rep. 2014 Feb 26;4:4133. doi: 10.1038/srep04133.

7. Farsalinos KE, Spyrou A, Stefopoulos C, Tsimopoulou K, Kourkoveli P, Tsiapras D, Kyrzopoulos S, Poulas K, Voudris V. Nicotine absorption from electronic cigarette use: comparison between experienced consumers (vapers) and naïve users (smokers). Sci Rep. 2015 Jun 17;5:11269. doi: 10.1038/srep11269. Erratum in: Sci Rep. 2015;5:13506.

8. Farsalinos KE, Barbouni A. Association between electronic cigarette use and smoking cessation in the European Union in 2017: analysis of a representative sample of 13057 Europeans from 28 countries. Tob Control. 2021 Jan;30(1):71-76. doi: 10.1136/tobaccocontrol-2019-055190.

9. The Investigative Desk. Funding and Independence. Available at: https://investigativedesk.com/about/.

10. University of Bath. New Supplier Application Form. Available at: https://tinyurl.com/45sz779n. Document obtained through a Freedom of Information Act request.

11. University of Bath. Contract for Services Schedule. Available at: https://tinyurl.com/dts3hcp3. Document obtained through a Freedom of Information Act request.

12. University of Bath. Reference: New Supplier Form for Investigative Desk. Available at: https://tinyurl.com/h9f8h5ht. Document obtained through a Freedom of Information Act request.

13. Gunther M. Bloomberg's Millions Funded an Effective Campaign Against Vaping. Could It Do More Harm Than Good? The Chronicle of Philanthropy. Available at:

https://www.philanthropy.com/article/bloombergs-millions-funded-an-effective-campaign-againstvaping-could-it-do-more-harm-than-good.

14. Clive Bates. Holding the Bloomberg anti-vaping propaganda complex to account. Available at: https://www.clivebates.com/holding-the-bloomberg-anti-vaping-propaganda-complex-to-account/.

15. Burning Issues: The Global State of Tobacco Harm Reduction 2020. Available at: https://gsthr.org/resources/item/burning-issues-global-state-tobacco-harm-reduction-2020.

16. Farsalinos K, Eliopoulos E, Leonidas DD, Papadopoulos GE, Tzartos S, Poulas K. Nicotinic Cholinergic System and COVID-19: In Silico Identification of an Interaction between SARS-CoV-2 and Nicotinic Receptors with Potential Therapeutic Targeting Implications. Int J Mol Sci. 2020 Aug 13;21(16):5807. doi: 10.3390/ijms21165807. 
17. Williamson EJ, Walker AJ, Bhaskaran K, Bacon S, Bates C, Morton CE, Curtis HJ, Mehrkar A, Evans D, Inglesby P, Cockburn J, McDonald HI, MacKenna B, Tomlinson L, Douglas IJ, Rentsch CT, Mathur R, Wong AYS, Grieve R, Harrison D, Forbes H, Schultze A, Croker R, Parry J, Hester F, Harper S, Perera R, Evans SJW, Smeeth L, Goldacre B. Factors associated with COVID-19-related death using OpenSAFELY. Nature. 2020 Aug;584(7821):430-436. doi: 10.1038/s41586-020-2521-4.

18. Hippisley-Cox J, Tan PS, Coupland C. Risk of severe COVID-19 disease with ACE inhibitors and angiotensin receptor blockers: cohort study including 8.3 million people. Heart. 2020 Nov 5:heartjnl2020-318312. doi: 10.1136/heartjnl-2020-318312.

19. Kowall B, Nonnemacher M, Brune B, Brinkmann M, Dudda M, Böttcher J, Schmidt B, Standl F, Stolpe S, Dittmer $\mathrm{U}$, Jöckel $\mathrm{KH}$, Stang A. A model to identify individuals with a high probability of a SARS-CoV-2 infection. J Infect. 2021 Mar;82(3):e32-e34. doi: 10.1016/j.jinf.2020.11.028.

20. Rossato M, Russo L, Mazzocut S, Di Vincenzo A, Fioretto P, Vettor R. Current smoking is not associated with COVID-19. Eur Respir J. 2020 Jun 4;55(6):2001290. doi: 10.1183/13993003.01290-2020.

21. Docherty AB, Harrison EM, Green CA, Hardwick HE, Pius R, Norman L, Holden KA, Read JM, Dondelinger F, Carson G, Merson L, Lee J, Plotkin D, Sigfrid L, Halpin S, Jackson C, Gamble C, Horby PW, Nguyen-VanTam JS, Ho A, Russell CD, Dunning J, Openshaw PJ, Baillie JK, Semple MG; ISARIC4C investigators. Features of 20133 UK patients in hospital with covid-19 using the ISARIC WHO Clinical Characterisation Protocol: prospective observational cohort study. BMJ. 2020 May 22;369:m1985. doi: 10.1136/bmj.m1985.

22. Fontanet A, Tondeur L, Madec Y, Grant R, Besombes C, Jolly N, Pellerin SF, Ungeheuer MN, Cailleau I, Kuhmel L, Temmam S, Huon C, Chen KY, Crescenzo B, Munier S, Demeret C, Grzelak L, Staropoli I, Bruel T, Gallian P, Cauchemez S, van der Werf S, Schwartz O, Eloit M, Hoen B. Cluster of COVID-19 in northern France: A retrospective closed cohort study. medRxiv 2020.04.18.20071134; doi: https://doi.org/10.1101/2020.04.18.20071134.

23. Israel A, Feldhamer I, Lahad A, Levin-Zamir D, Lavie G. Smoking and the risk of COVID-19 in a large observational population study. medRxiv 2020.06.01.20118877; doi: https://doi.org/10.1101/2020.06.01.20118877.

24. Iruretagoyena M, Vial MR, Spencer-Sandino M, Gaete P, Peters A, Delgado I, Perez I, Calderon C, Porte L, Legarraga P, Anderson A, Aguilera X, Vial P, Weitzel T, Munita JM. Longitudinal assessment of SARS-CoV2 IgG seroconversionamong front-line healthcare workers during the first wave of the Covid-19 pandemic at a tertiary-care hospital in Chile. BMC Infect Dis. 2021 May 26;21(1):478. doi: 10.1186/s12879-021-06208-2.

25. Petrilli CM, Jones SA, Yang J, Rajagopalan H, O'Donnell L, Chernyak Y, Tobin KA, Cerfolio RJ, Francois F, Horwitz LI. Factors associated with hospital admission and critical illness among 5279 people with coronavirus disease 2019 in New York City: prospective cohort study. BMJ. 2020 May 22;369:m1966. doi: 10.1136/bmj.m1966.

26. Lee SC, Son KJ, Kim DW, Han CH, Choi YJ, Kim SW, Park SC. Smoking and the risk of severe acute 
respiratory syndrome coronavirus 2 (SARS-CoV-2) infection. Nicotine Tob Res. 2021 Apr 23:ntab079. doi: 10.1093/ntr/ntab079.

27. Farsalinos K, Niaura R, Le Houezec J, Barbouni A, Tsatsakis A, Kouretas D, Vantarakis A, Poulas K. Editorial: Nicotine and SARS-CoV-2: COVID-19 may be a disease of the nicotinic cholinergic system. Toxicol Rep. 2020 Apr 30;7:658-663. doi: 10.1016/j.toxrep.2020.04.012.

28. Tracey KJ. The inflammatory reflex. Nature. 2002 Dec 19-26;420(6917):853-9. doi: 10.1038/nature01321.

29. ClinicalTrials.gov. Efficacy of Nicotine in Preventing COVID-19 Infection (NICOVID-PREV). Available at: https://clinicaltrials.gov/ct2/show/NCT04583410.

30. ClinicalTrials.gov. Evaluation of the Efficacy of Nicotine Patches in SARS-CoV2 (COVID-19) Infection in Intensive Care Unit Patients (NICOVID-REA). Available at: https://clinicaltrials.gov/ct2/show/NCT04598594.

31. Ahmad F. COVID-19 induced ARDS, and the use of galantamine to activate the cholinergic antiinflammatory pathway. Med Hypotheses. 2020 Dec;145:110331. doi: 10.1016/j.mehy.2020.110331. 